\title{
On-Line Bioaffinity-Electrospray Mass Spectrometry for Simultaneous Detection, Identification, and Quantification of Protein-Ligand Interactions
}

\author{
Mihaela Dragusanu, ${ }^{a}$ Brîndusa-Alina Petre, ${ }^{a}$ Stefan Slamnoiu, ${ }^{a}$ \\ Camelia Vlad, ${ }^{a}$ Tingting $\mathrm{Tu},{ }^{\mathrm{b}}$ and Michael Przybylski ${ }^{\mathrm{a}}$ \\ a Laboratory of Analytical Chemistry and Biopolymer Structure Analysis, Department of Chemistry, \\ University of Konstanz, Konstanz, Germany \\ ${ }^{\mathrm{b}}$ Department of Chemistry, Washington University, St. Louis, Missouri, USA
}

We describe here an on-line combination of a surface acoustic wave (SAW) biosensor with electrospray ionization mass spectrometry (SAW-ESI-MS) that enables the direct detection, identification, and quantification of affinity-bound ligands from a protein-ligand complex on a biosensor chip. A trapping column was used between the SAW-biosensor and the electrospray mass spectrometer equipped with a micro-guard column, which provides simultaneous sample concentration and desalting for the mass spectrometric analysis of the dissociated ligand. First applications of the on-line SAW-ESI-MS combination include (1), differentiation of $\beta$-amyloid (A $\beta$ ) epitope peptides bound to anti-A $\beta$ antibodies; (2), the identification of immobilized Substance P peptide-calmodulin complex; (3), identification and quantification of the interaction of 3-nitrotyrosine-modified peptides with nitrotyrosine-specific antibodies; and (4), identification of immobilized anti- $\alpha$-synuclein-human $\alpha$-synuclein complex. Quantitative determinations of protein-ligand complexes by SAW yielded dissociation constants $\left(\mathrm{K}_{\mathrm{D}}\right)$ from micro-to low nanomolar sample concentrations. The on-line bioaffinity-ESI-MS combination presented here is expected to enable broad bioanalytical application to the simultaneous, label-free determination and quantification of biopolymer-ligand interactions, as diverse as antigen-antibody and lectin-carbohydrate complexes. (J Am Soc Mass Spectrom 2010, 21, 1643-1648) (c) 2010 Published by Elsevier Inc. on behalf of American Society for Mass Spectrometry

$\mathrm{A}$ number of affinity-based methods have been established during the past years for the detection and quantification of biomolecular interactions. Methods widely used for characterization of protein-ligand interactions include immunoaffinityanalysis by ELISA and Western blot [1], isothermal titration calorimetry (ITC) [2], and surface plasmon resonance (SPR) [3, 4]. In particular, SPR has developed into an efficient tool for analysis of biomolecular recognition processes at a biosensor surface, and has been applied to the quantification of a variety of biopolymer interactions [4, 5]. A recently-explored alternative to SPR is the surface acoustic wave (SAW) technology in which the piezoelectric effect of mass differences is employed for bioaffinity detection [6-9]. SAW is now becoming increasingly important for the study of biomacromolecular interactions due to its high detection sensitivity in dilute solutions.

Address reprint requests to Dr. Michael Przybylski, Department of Chemistry, University of Konstanz, 78457 Konstanz, Germany. E-mail: Michael. Przybylski@uni-konstanz.de
Advantages of SAW in comparison to classical immuno-analytical techniques are the direct and rapid determination of association/dissociation constants with small sample amounts, and without labeling approaches or recalibration for buffer changes being required [6]. While providing sensitive and accurate determinations of binding/dissociation constants $\left(\mathrm{K}_{\mathrm{i}}\right.$ or $\left.\mathrm{K}_{\mathrm{D}}\right)$, a major limitation of all bioaffinity methods is the lack of direct identification of the affinity-bound ligands. In contrast, the combination of biosensor detection and mass spectrometry enables both identification and quantification of bioaffinity interactions of biopolymers. Here we describe an on-line combination of an SAW biosensor with electrospray ionization mass spectrometry, SAW-ESI-MS. The on-line coupling between the SAW-sensor chip and the ESI-MS source was achieved by a incorporating a standard trapping column setup, using a six-port valve, a guard column, and a micropump system. The six-port valve interface provides both ligand concentration and an in situ desalting step for the dissociated biopolymerligand complex.

Our first applications of the on-line SAW-ESI-MS 
include the simultaneous identification and quantification of $\beta$-amyloid $(\mathrm{A} \beta)$ peptides bound to anti- $\mathrm{A} \beta$ antibodies, 3-nitrotyrosine-modified peptides bound to a nitrotyrosine-specific antibody, calmodulin-peptide complex, and an $\alpha$-synuclein antibody-human $\alpha$-synuclein $(\alpha$-Syn) complex [10-13]. Determinations of dissociation constants of the peptide- and antibody complexes illustrate the successful application of the SAW-ESI-MS combination for solution concentrations in the micro-to low nanomolar range. These results suggest a broad range of potential applications for the on-line SAWbioaffinity-ESI-MS combination for the simultaneous detection, structural characterization, and quantification of biopolymer-ligand complexes.

\section{Experimental}

\section{Antibodies and Chemicals}

Monoclonal anti-A $\beta$ antibodies, anti-3-nitro-tyrosine antibody, and polyclonal anti- $\alpha$-synuclein antibody were obtained from Covance (Emeryville, CA, USA), Chemicon (Millipore, Schwalbach, Germany) and Santa Cruz (Heidelberg, Germany). N-hydroxysuccinimide (NHS), N- $\alpha$-Fmoc protected amino acids, 1-ethyl-3-[3dimethylaminopropyl]-carbodiimide (EDC), and other reagents for peptide synthesis were obtained from Merck (Darmstadt, Germany), Sigma (Schnelldorf, Germany), and NovaBiochem (Laufelfingen, Switzerland). $\mathrm{N}$ - $\alpha$-Fmoc-3-nitro-tyrosine was from Bachem (Bubendorf, Switzerland). $\alpha$-Synuclein was obtained from rPeptide (Bogart, GA, USA). Bovine calmodulin and Substance $\mathrm{P}$ were obtained from Calbiochem (Darmstadt, Germany). Other reagents and solvents used were obtained with highest available purities from Fluka (Darmstadt, Germany). 3-Nitrotyrosine-peptides and $\mathrm{A} \beta$-peptides were synthesized by solid-phase peptide synthesis (SPPS) on a semi-automated peptide synthesizer (EPS-221; Intavis, Langenfeld, Germany) as previously described $[11,13]$. Purification of crude peptides was performed by RP-HPLC on a semi-preparative UltiMate 3000 HPLC system (Dionex, Germering, Germany).

\section{On-Line SAW-ESI-MS}

The K5-SSens Biosensor used (SAW-Instruments, Bonn, Germany) is a chip-based bioaffinity system for markerfree detection of affinity interactions, and is based on the conversion of a high-frequency signal into a surface acoustic wave (SAW) due to the inverse piezoelectric effect. The velocity of the SAW is sensitive to changes in mass loading and viscosity, causing shifts in the signal's amplitude and/or phase that enable high-sensitivity detection, unlike most other biosensors, which are equipped with a readout unit containing a microfluidic cell. Thus, interactions on the gold-coated chip surface can be observed at near-physiologic conditions [8].

The interface used for on-line coupling of SAW with
ESI-MS includes a six-port valve unit (Rheodyne; Idex, Wertheim-Mondfeld, Germany and C18-microguardcolumn (Optimize Technologies, Inc., Oregon City, OR, USA) and micro-injector for desalting and concentration of dissociated ligand samples (Figure 1). Antibody was immobilized on an SAM-gold chip, following formation of a self-assembled monolayer (SAM) surface of 16mercaptohexadecanoic acid, for $12 \mathrm{~h}$ at $25^{\circ} \mathrm{C}$ [14]. SAMcarboxyl groups were activated with $200 \mathrm{mM} \mathrm{N}-(3-$ dimethylaminopropyl)-N-ethylcarbodiimide (EDC); coupling was carried out using $50 \mathrm{mM}$ NHS followed by washing of the chip surface with $40 \mu \mathrm{L} \mathrm{min}{ }^{-1} \mathrm{H}_{2} \mathrm{O}$. A solution of $300 \mathrm{nM}(150 \mu \mathrm{L})$ antibody was immobilized on the SAM, and any remaining NHS groups were blocked with $1 \mathrm{M}$ ethanolamine ( $\mathrm{pH}$ 8.5). A $10 \mu \mathrm{M}$ solution of peptide ligand mixture was added and affinity binding performed at a flow rate of $20 \mu \mathrm{L} \mathrm{min}{ }^{-1}$. All affinity binding experiments were performed at $20^{\circ} \mathrm{C}$ in PBS binding buffer, $\mathrm{pH}$ 7.5. Following the association of the ligand, elution was carried out with glycine buffer or $\mathrm{HCl}$, and removal of buffer salts was performed by washing with $0.3 \%$ aqueous $\mathrm{HCOOH}$ and elution and transfer into the ESI source was done with $0.3 \%$ $\mathrm{HCOOH} / 80 \%$ acetonitrile (elution), by switching the position of the microvalve (see Figure 1). A Bruker Esquire $3000+$ ion trap mass spectrometer was used for on-line SAW-ESI-MS (Bruker Daltonik, Bremen, Germany). A $0.3 \% \mathrm{HCOOH} / 80 \%$ acetonitrile solution was used for transfer of the eluted ligands into the ESI source at a flow rate of $70 \mu \mathrm{L} \mathrm{min}{ }^{-1}$. Mass spectra were recorded in full-scan mode, mass range 200-2000 Th, with 20 psi nebulizer gas, $10.0 \mathrm{~L} \mathrm{~min}^{-1}$ drying gas, and $200{ }^{\circ} \mathrm{C}$ ion source temperature.

An efficient interface between the SAW-biosensor and the ESI-MS was used by assembly of a six-port micro-valve injection system equipped with a $40 \mu \mathrm{m}$ micro-guard column (Figure 1). The biosensor exit capillary was connected to the six-port valve-interface (position 6), with the ESI-MS inlet capillary connected to position 3 (flow 1, Figure 1a). Following association of ligand (PBS buffer), dissociation is performed by elution with $150 \mu \mathrm{L}$ acidic glycine buffer or $\mathrm{HCl}$ at 20-40 $\mu \mathrm{L} \mathrm{min}^{-1}$ into the guard column, and removal of buffer salt is accomplished by washing with $\mathrm{HCOOH}$. Elution with aqueous $0.3 \% \mathrm{HCOOH} / 80 \%$ acetonitrile and transfer of the sample into the ESI source is then performed by simple switching of the micro-valve/ injector (flow 2; Figure 1b). A simple micro-pumping system is used for elution; with the present interface a standard fused silica capillary (ID $150 \mu \mathrm{m}$ ) was used.

Determination of dissociation constants was performed after covalent immobilization of the binder to the activated Au-SAM using $150 \mu \mathrm{L}$ of different concentrations of the ligand $(1 \mathrm{nM}-1 \mu \mathrm{M})$ at $20 \mu \mathrm{L} \mathrm{min}{ }^{-1}$ flow rate of. Affinity binding experiments were done in PBS buffer $\mathrm{pH} 7.5$, and than $150 \mu \mathrm{L}$ of $350 \mathrm{nM}$ antilysozyme antibody was added as a control to block unspecific binding sites, followed by regeneration with $150 \mu \mathrm{L}$ glycine buffer, $\mathrm{pH} 2$. Association kinetics were 


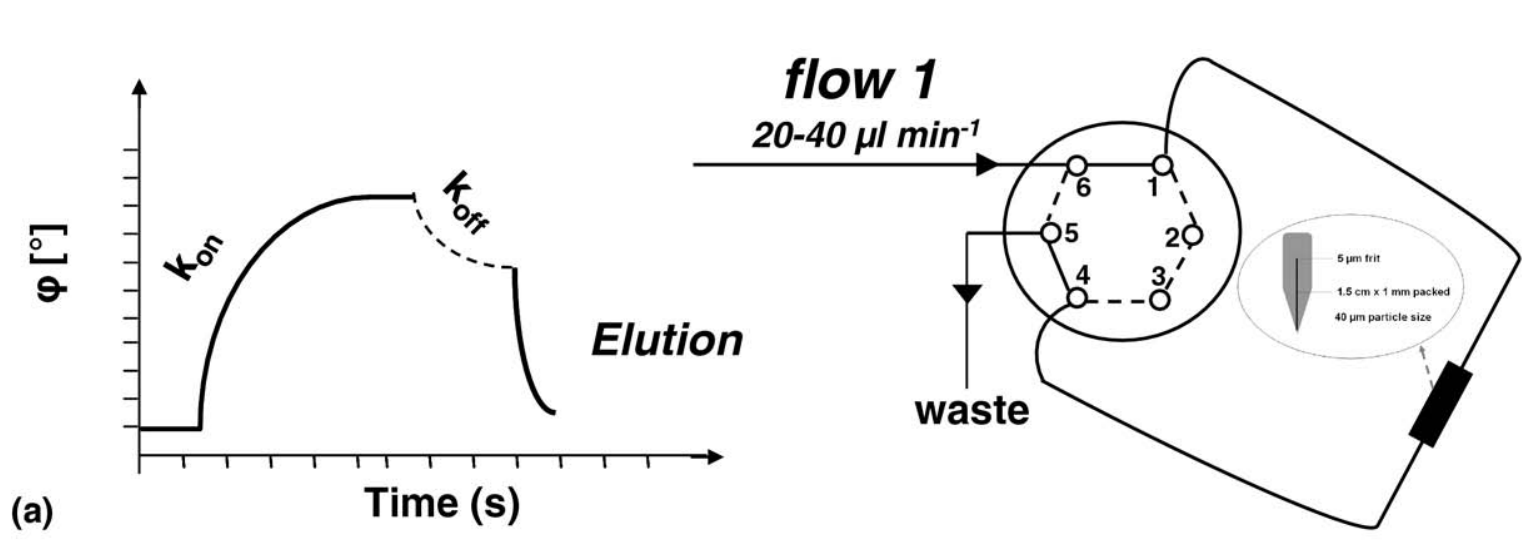

(a)
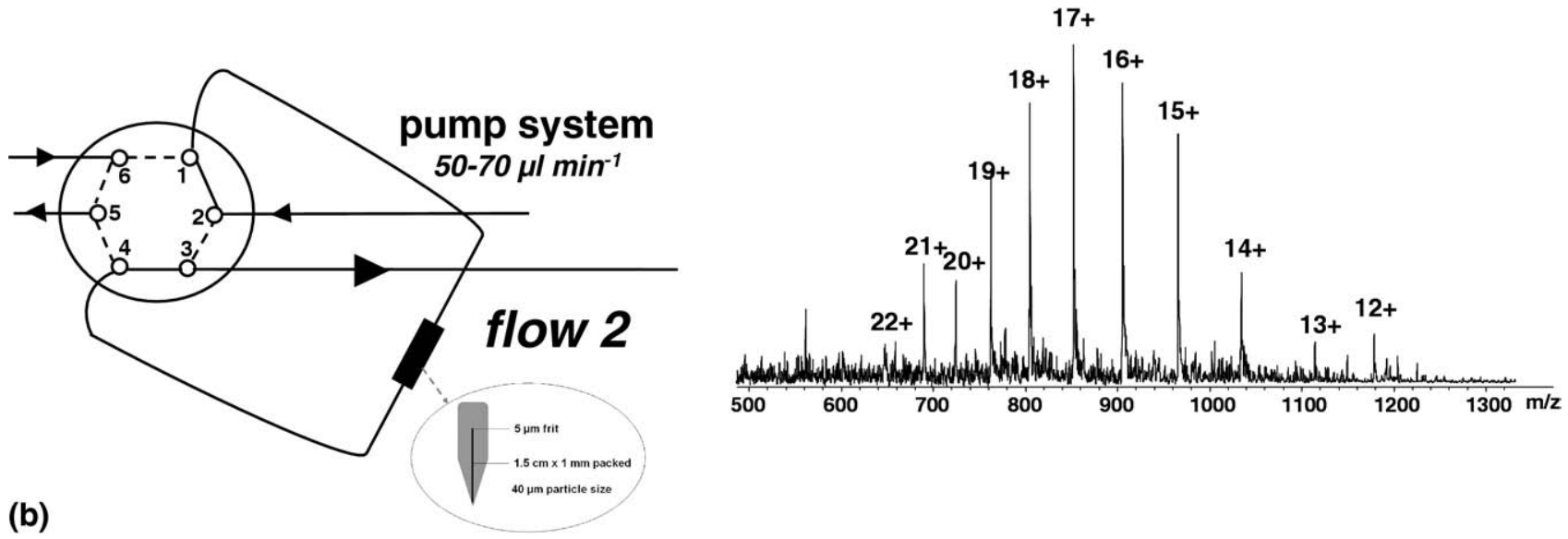

(b)

\begin{abstract}
Figure 1. Schematic of the on-line SAW-ESI-MS combination using an SSens/K5-SAW biosensor and a six-port-valve micro-column interface. (a) The biosensor exit capillary is connected to the interface in position 6, with the ESI-MS inlet capillary in position 3. Dissociation of the ligand from the SAM-Chip is performed by eluting with acidic glycine buffer or hydrochloric acid into the microcolumn interface (flow 1). (b) Removal of buffer salt solution and transfer of the eluate into the ESI source by switching the interface valve to position inject, and elution with aqueous acetonitrile/ $\mathrm{HCOOH}$ as described in the Experimental section (flow 2).
\end{abstract}

determined with serial dilutions from $1 \mathrm{nM}-1 \mu \mathrm{M}$, followed by regeneration with glycine buffer. Determination of antibody/protein association kinetics was performed by extracting the data from the sensor signals for all concentrations employed, using the monomolecular growth model [14]. Determinations of dissociation constants was performed by plotting the pseudo first-order kinetic constant versus concentration, and applying linear regression for $\mathrm{K}_{\mathrm{D}}=\mathrm{k}_{\text {off }} \mathrm{k}_{\mathrm{on}}{ }^{-1}$.

\section{Results and Discussion}

\section{Interface for On-Line Bioaffinity-ESI-MS}

Bioaffinity determination by SAW in most cases requires the application of high concentrations of buffer salts at physiological $\mathrm{pH}$, which presents a major problem for subsequent mass spectrometric analysis. A further problem for the on-line SAW-MS combination is the relatively high flow rate of the SAW-biosensor, which leads to significant dilution of the eluted ligand; hence an interface is required for desalting and concentration of sample solutions for mass spectrometric analysis.
The interface presented in Figure 1 provides realtime mass spectrometric analysis of SAW-ligands dissociated from the chip-binder surface, and has shown stable long-term operation with minimal contamination of the ESI-MS. In contrast, SPR-LC-MS (MS/MS) combinations have been previously reported, in which either proteolytic peptides of proteins isolated on an SPR chip were analyzed, or captured molecules reanalyzed by LC-MS [15-17]. Offline isolation of biosensor detected ligands followed by MALDI-MS has also been reported, but the relation to the biosensor signal quantification is lost in this approach [18, 19].

\section{Interaction Analysis of Tyrosine-Nitrated Peptides to an Anti-Nitrotyrosine Antibody by On-Line $S A W-M S$}

The nitration of proteins at tyrosine residues has recently become of great interest due to the importance of this modification in oxidative stress and the corresponding toxic effects on cellular proteins. Specific nitrations of tyrosine residues have been identified 
upon treatment with peroxynitrite, and recently by enzymatic reaction in eosinophile granulocytes, and the use of 3-nitrotyrosine-specific antibodies has been essential for the mass spectrometric identification of Tyrnitrations using proteolytic affinity-MS [12, 13].

In prostacyclin synthase (PCS), a specific nitration by peroxynitrite has been identified at the tyrosine- 430 residue near the catalytic center, which inactivates the enzyme [12]. For a comparative study on the specificity of nitration using on-line SAW-MS, nitrated PCS peptides were synthesized at Tyr-430 and at other Tyr residues (3, Tyr421; 4, Tyr-83; 5, Tyr-430; Figure 2 and Table 1). SAW-Affinity binding curves of an equimolar mixture $(10 \mu M)$ of the nitrated peptides 3,4 , and 5 and mass spectrometric characterization of the eluted peptides in on-line SAW-MS from the immobilized antibody are shown in Figure $2 \mathrm{a}-\mathrm{e}$ ). The mass spectrum of the mixture of the eluted peptides showed that the $[\mathrm{M}+2 \mathrm{H}]^{2+}$ ion of the Tyr-430-nitrated peptide 5 had the highest abundance, suggesting higher affinity to the nitrotyrosine-antibody (Figure 2d), while the elution of a mixture of Tyr-430-nitrated and non-nitrated peptides (5 and 6) provided only ions of the nitrated peptide (Figure 2e).

SAW-Determinations of dissociation constants were performed with the SAM-immobilized peptides, and provided a $K_{D}$ of $\sim 60 \mathrm{nM}$ for the Tyr-430 nitrated peptide (Table 1), while other nitrated peptides showed significantly lower affinities, consistent with a specific epitope motif for Tyr-nitrated sequences with adjacent basic residues (Dragusanu et al., submitted for publication).

The high sensitivity of the SAW biosensor and the wide range of immobilization procedures compatible with the SAM gold chip provide convenient conditions for the determination of affinities for a broad range of protein-ligand interactions using the on-line SAW-MS. Examples of $\mathrm{K}_{\mathrm{D}}$ determinations obtained from SAWESI-MS analysis are shown in Table 1. Using a monoclonal anti-A $\beta(1-16)$ antibody, the mass spectrometric provided the identification of the $\mathrm{Glu}^{3}-\mathrm{A} \beta(3-40)$ peptide and showed that a truncated $\mathrm{N}$-terminal peptide was recognized by the antibody, consistent with the previous identification of the $\mathrm{N}$-terminal epitope, $\mathrm{A} \beta(4-10)$ $[10,11]$. For the calmodulin-Substance $\mathrm{P}$ complex, a $\mathrm{K}_{\mathrm{D}}$ of $\sim 44 \mathrm{nM}$ was obtained indicating a somewhat higher affinity of the complex in comparison to the $2 \mu \mathrm{M}$ value determined by an earlier study [20]. One of the antibody complex illustrated in Table 1, $\alpha$-Syn antibody- $\alpha$ Syn complex was analyzed because $\alpha$-Syn antibodies

\section{$3: \mathrm{H}-\mathrm{EKKDFY}{ }^{421}\left(\mathrm{NO}_{2}\right)$ KDGKRL-OH 4 : H- DPHSY83 $\left(\mathrm{NO}_{2}\right)$ DAVVWEPR-OH $\underline{5}: \mathrm{H}-$ GKRLKNY ${ }^{430}\left(\mathrm{NO}_{2}\right)$ SLPWGA}

(b)

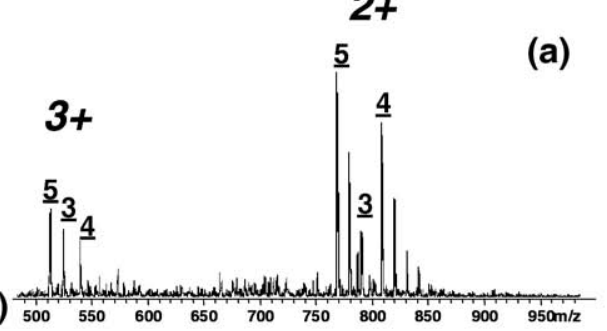

$2+$

(d)

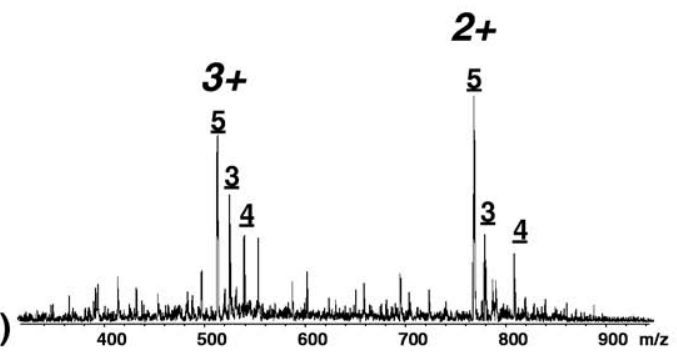

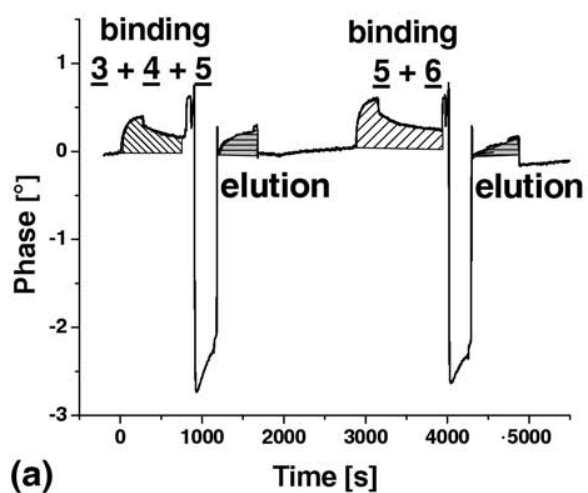

$\underline{5}: \mathrm{H}-\mathrm{GKRLKNY}{ }^{430}\left(\mathrm{NO}_{2}\right)$ SLPWGA-OH $\underline{6}:$ H- GKRLKNY ${ }^{430}$ SLPWGA-OH

binding (c)

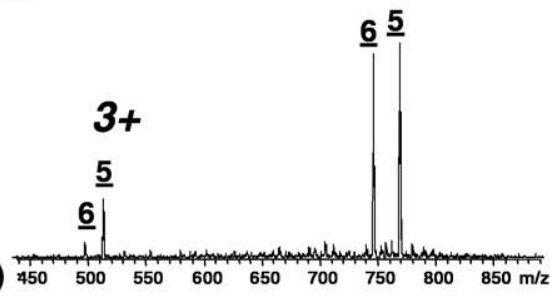

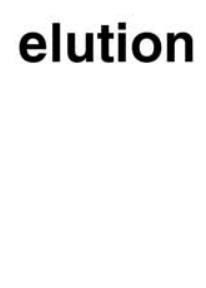

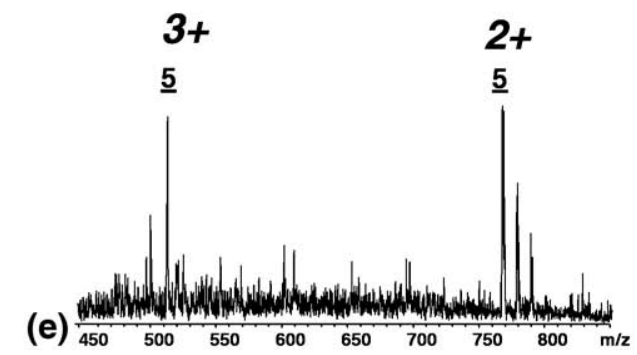

Figure 2. SAW Binding curves obtained using on-line SAW-ESI-MS (a), ESI-MS spectra of the binding mixture presented to the SAW Biosensor (b), (c), and mass spectrometric identification of Tyr-nitrated peptide mixtures 3, 4, 5 from an immobilized monoclonal anti-3-nitrotyrosine antibody (MAB5404; Chemicon) (d), (e). 
Table 1. Mass spectrometric identification and $\mathrm{K}_{\mathrm{D}}$ determinations of protein (antibody) binder- ligand complexes by online SAW-ESI-MS

\begin{tabular}{|c|c|c|c|c|}
\hline \multicolumn{2}{|c|}{ Binder-ligand system } & \multirow[b]{2}{*}{$m / z^{c}$} & \multirow[b]{2}{*}{$z^{d}$} & \multirow[b]{2}{*}{$K_{D}\left(10^{-9} M\right)$} \\
\hline Binder & Peptide ligand & & & \\
\hline$A \beta(1-16)$ antibody $^{a}$ & 1: Glu3 A $\beta(3-40)$ & 710.3 & $6+$ & $106.9 \pm 14.1^{\mathrm{e}}$ \\
\hline \multirow{3}{*}{ Anti 3-NT antibody ${ }^{a}$} & 3: H-EKKDFY ${ }^{421}\left(\mathrm{NO}_{2}\right)$ KDGKRL-OH & 808.1 & $2+$ & $80^{f}$ \\
\hline & 4: H-DPHSY ${ }^{83}\left(\mathrm{NO}_{2}\right)$ DAVVWEPR-OH & 786.6 & $2+$ & $150^{f}$ \\
\hline & 5: H-GKRLKNY ${ }^{430}\left(\mathrm{NO}_{2}\right)$ SLPWGA-OH & 767.7 & $2+$ & $63 \pm 20^{g}$ \\
\hline \multirow[t]{2}{*}{ Anti 3-NT antibody ${ }^{a}$} & 5: H-GKRLKNY ${ }^{430}\left(\mathrm{NO}_{2}\right)$ SLPWGA-OH & 768.2 & $2+$ & $63 \pm 20^{9}$ \\
\hline & 6: H-GKRLKNY ${ }^{430}$ SLPWGA-OH & 745.6 & $2+$ & $-{ }^{h}$ \\
\hline Substance P & 7: Calmodulin & 1866.0 & $9+$ & $43.6 \pm 15.8^{\mathrm{e}}$ \\
\hline Anti $\alpha$-Syn (C-20)-R antibody ${ }^{b}$ & 8: h $\alpha$-Synuclein & 851.8 & $17+$ & $164.7 \pm 17.5^{\mathrm{e}}$ \\
\hline
\end{tabular}

aThe antibodies were monoclonal.

bThe antibody was polyclonal.

"Most abundant ligand ion identified by SAW-ESI-MS.

${ }^{\mathrm{d}}$ Charge of the most abundant ligand ion identified by SAW-ESI-MS

e Determination of $K_{D}$ was performed with the binder immobilized on SAM-surface.

${ }^{f} K_{D}$ values were estimated from the affinity-mass spectrometry measurements.

gDetermination of the $\mathrm{K}_{\mathrm{D}}$ was done in a separate experiment with immobilized peptide 5 on the SAM-surface.

hPeptide 6 showed no affinity to the anti 3-NT antibody.

have been extensively employed in studies of this protein, which is strongly correlated with one of the most common neurodegenerative motor disorders, Parkinson's disease [21]. No details about affinity binding and $\mathrm{K}_{\mathrm{D}}$ determination of this $\alpha$-synuclein specific antibody have been previously reported.

\section{Conclusions}

In this study, we have developed an efficient on-line SAW-biosensor-MS system for the simultaneous identification and quantification of protein-ligand interactions. The $\mathrm{K}_{\mathrm{D}}$ determinations obtained indicate a wide range of affinities amenable, ranging from nanomolar (antibodies) to sub-micromolar (lectin-carbohydrate complexes; data not shown). The on-line SAW-MS system presented requires only a standard pump system. It is amenable with a broad range of chip-immobilization techniques and is well feasible to MS/MS analysis (data not shown). Hence, on-line SAW-ESI-MS should develop into an efficient and sensitive tool for label-free detection, identification, and quantification of biopolymer-ligand interactions.

\section{Acknowledgments}

The authors acknowledge support for this study by the DAAD, Bonn, Germany (ppp-502/09), the Deutsche Forschungsgemeinschaft (DFG), Bonn, Germany (PR 818/07), and the Graduate School Chemical Biology, University of Konstanz. The authors thank Dr. Thomas Gronewold and Dr. Markus Perpeet for assistance and helpful discussions of the SAW technology.

\section{References}

1. Orosz, F.; Ovádi, J. A Simple Method for the Determination of Dissociation Constants by Displacement ELISA. J. Immunol. Methods 2002, 270, 155-162.

2. Feig, A. L. Applications of Isothermal Titration Calorimetry in RNA Biochemistry and Biophysics. Biopolymers 2007, 87, 293-301.
3. Coille, I.; Gauglitz, G.; Johan, H. Characterization of Antibodies and Analytes by Surface Plasmon Resonance for the Optimization of a Competitive Immunoassay Based on Energy Transfer. Anal. Bioanal. Chem. 2002, 372, 293-300.

4. Homola, J. Surface Plasmon Resonance Sensors for Detection of Chemical and Biological Species. Chem. Rev. 2008, 108, 462-493.

5. Ayela, C.; Roquet F.; Valera, L.; Granier, C.; Nicu, L.; Pugnière, M. Antibody-Antigenic Peptide Interactions Monitored by SPR and QCM-D: A Model for SPR Detection of IA-2 Autoantibodies in Human Serum. Biosens. Bioelectronics 2007, 22, 3113-3119.

6. Perpeet, M.; Glass, S.; Gronewold, T.; Kiwitz, A.; Malaveacute, A.; Stoyanov, I.; Tewes, M.; Quandt, E. SAW Sensor System for MarkerFree Molecular Interaction Analysis, Anal. Lett. 2006, 39, 17471757.

7. Lange, K.; Bender, F.; Voigt, A.; Gao, H.; Rapp, M. A Surface Acoustic Wave Biosensor Concept with Low Flow Cell Volumes for Label-Free Detection. Anal. Chem. 2003, 75, 5561-5566.

8. Lange, K.; Rapp, B.; Rapp, M. Surface Acoustic Wave Biosensors: A Review. Anal. Bioanal. Chem. 2008, 391, 1509-1519.

9. Rocha-Gaso, M.-I.; March-Iborra, C.; Montoya-Baides, Ã.; Arnau-Vives, A. Surface Generated Acoustic Wave Biosensors for the Detection of Pathogens: A Review. Sensors 2009, 9, 5740-5769.

10. McLaurin, J.; Cecal, R.; Kierstead, M. E.; Tian, X.; Phinney, A. L.; Manea, M.; French, J. E.; Lambermon, M. H.; Darabie, A. A.; Brown, M. E.; Janus, C.; Chishti, M. A.; Horne, P.; Westaway, D.; Fraser, P. E.; Mount, H. T.; Przybylski, M.; St George-Hyslop, P. Therapeutically Effective Antibodies Against Amyloid- $\beta$ Peptide Target Amyloid- $\beta$ Residues 4-10 and Inhibit Cytotoxicity and Fibrillogenesis Nature Med. 2002, 8, 1263-1269.

11. Juszczyk, P.; Paraschiv, G.; Szymanska, A.; Kolodziejczyk, A. S.; Rodziewicz-Motowidlo, S.; Grzonka, Z.; Przybylski, M. Binding Epitopes and Interaction Structure of the Neuroprotective Protease Inhibitor Cystatin $C$ with $\beta$-Amyloid Revealed by Proteolytic Excision Mass Spectrometry and Molecular Docking Simulation. J. Med. Chem. 2009, 52, 2420-2428.

12. Schmidt, P.; Youhnovski, N.; Daiber, A.; Balan, A.; Arsic, M.; Bachschmid, M.; Przybylski, M.; Ullrich, V. Specific Nitration at Tyrosine 430 Revealed by High Resolution Mass Spectrometry as Basis for Redox Regulation of Bovine Prostacyclin Synthase. J. Biol. Chem. 2003, 278, 12813-12819.

13. Ulrich, M.; Petre, A.; Youhnovski, N.; Promm, F.; Schirle, M.; Schumm, M.; Pero, R. S.; Doyle, A.; Checkel, J.; Kita, H.; Thiyagarajan, N.; Acharya, K. R.; Schmid-Grendelmeier, P.; Simon, H. U.; Schwarz, H.; Tsutsui, M.; Shimokawa, H.; Bellon, G.; Lee, J. J.; Przybylski, M.; Doring, G. Post-Translational Tyrosine Nitration of Eosinophil Granule Toxins Mediated by Eosinophil Peroxidase. J. Biol. Chem. 2008, 283, 2862928640.

14. Gronewold, T. M. Surface Acoustic Wave Sensors in the Bioanalytical Field: Recent Trends and Challenges. Anal. Chim. Acta 2007, 603, 119-128.

15. Hayano, T.; Yamauchi, Y.; Asano, K.; Tsujimura, T.; Hashimoto, S.; Isobe, T.; Takahashi, N. Automated SPR-LC-MS/MS System for Protein Interaction Analysis J. Proteome Res. 2008, 7, 41834190 .

16. Marchesini, G. R.; Buijs, J.; Haasnoot, W.; Hooijerink, D.; Jansson, O.; Nielen, M. W. Nanoscale Affinity Chip Interface for Coupling Inhibition 
SPR Immunosensor Screening with Nano-LC TOF MS. Anal. Chem. 2008, 80, 1159-1168

17. Stigter, E. C. A.; de Jong, G. J.; van Bennekom, W. P. Development of an On-Line SPR-Digestion-NanoLC-MS/MS System for the Quantification and Identification of Interferon- $\gamma$ in Plasma. Biosens. Bioelectron. 2009, $24,2184-2190$.

18. Treitz, G.; Gronewold, T. M.; Quandt, E.; Zabe-Kuhn, M. Combination of a SAW-Biosensor with MALDI Mass Spectrometric Analysis. Biosens. Bioelectron. 2008, 23, 1496-1502.
19. Nedelkov, D.; Nelson, R. W. Surface Plasmon Resonance Mass Spectrometry for Protein Analysis. In Methods in Molecular Biology, Vol CCCXXVIII; Nedelkov, D.; Nelson, R. W., Eds.; Humana Press: Totowa, NJ, 2006; pp 131-139.

20. Malencik, D. A.; Anderson, S. R. Binding of Simple Peptides, Hormones, and Neurotransmitters by Calmodulin. Biochemistry 1982, 21, 3480-3486.

21. Forman, M. S.; Lee, V. M.; Trojanowski, J. Q. Nosology of Parkinson's Disease: Looking for the Way Out of a Quagmire. Neuron 2005, 47, $479-482$. 